\title{
Crowdfunding To Generate Crowdsourced R\&D: The Alternative Paradigm Of Societal Problem Solving Offered By Second Generation Innovation And R\&D
}

Chris William Callaghan, University of the Witwatersrand, South Africa

\begin{abstract}
In a global context of resource scarcity few incentives exist for firms to pursue innovations that provide social externalities if these are not inherently profitable. The purpose of this article is to present an alternative paradigm of societal problem solving entirely premised on 'second generation innovation' processes. Further, a theoretical model of multidimensional, or three dimensional, knowledge creation is offered, together with the notion of a 'multiplier effect' that relates to how knowledge creation can increase exponentially when knowledge is not constrained by proprietary requirements. Second generation innovation is based on probabilistic processes that utilize and maximize economies of scale in pursuit of problem solving. Two processes that contribute to the potential of second generation innovation to solve societal problems are crowdfunding and crowdsourcing. It is argued that the processes required to enable a new paradigm in societal problem solving already exist. A further model is developed based on potential synergies between crowdfunding and crowdsourced research and development. This theoretical model predicts that $R \& D$ productivity can be accelerated significantly, and if applied in fields such as proteomics or medical research in general can accelerate increases in research output.
\end{abstract}

Keywords: Second Generation Innovation; Crowdsourcing; Crowdfunding; Medical Research; Proteomics

\section{INTRODUCTION}

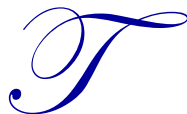

he world currently faces the prospect of catastrophic events, or disasters in which there is the threat of large-scale loss of human life. One possible example is the advent of a bioevent, or disease outbreak. In a world now connected by airline travel, this could be in the form of a global epidemic (Maher, 2013), in the form of, amongst others, the newly emerged Middle East Respiratory System Coronavirus (MERSCoV), Severe Acute Respiratory Syndrome (SARS)(BBC, 2013), or the H7N9 'Bird Flu' virus (Siu, Twinnie \& Pomfret, 2013). A research and development (R\&D) innovation pipeline, or supply of knowledge that can result in new medicines, is critically important (McKenna, 2014). This innovation pipeline is not only important to solve entirely new and emerging problems, but also for those that have previously been thought to be solved, but are reemerging.

Other examples of this particular threat are the emergence of diseases that decades ago were considered under control. Currently, Ebola has re-emerged in the form of a new epidemic that has broken out in West Africa (Krishnan, 2014). Polio has re-emerged in countries such as Pakistan (Zia, 2014) and Nigeria (Ajumobi, 2014) and fatal forms of tuberculosis have re-emerged in the form new strains of airborne tuberculosis that are now resistant to all forms of antibiotics (Maher, 2013). Increasingly, other forms of fatal bacteria have re-emerged; certain bacteria, or 'superbugs', are now totally resistant to, and others are increasingly resistant to, antibiotics (Halifax, 2013). Over two million people are currently infected with antibiotic resistant organisms (McKenna, 2014). Amidst decreasing global production and approvals of new antibiotics, certain commentators have therefore raised concerns that the 
innovation pipeline has slowed, or might be 'nearly broken' (McKenna, 2014). This is a dangerous state of affairs as the world might be facing a return to an era where even minor injuries and routine surgery are life-threatening (Halifax, 2013).

This article argues that the innovation pipeline is fundamentally unable to deal with challenges because the innovation pipeline is inherently coupled to the dictates of the market mechanism, which disproportionately allocates resources to other ends than those that are required to address global catastrophes. It is argued that marketdictated innovation and research and development (R\&D) belongs to a 'first generation' paradigm of innovation and R\&D. Although the market seems to be astonishingly effective at providing for most human needs, market failure is most prevalent when innovation is required that is not inherently profitable, notwithstanding the positive externalities that may arise later from such investments (Martin \& Scott, 2000). It is perhaps only social innovation that has the answers to these challenges, because of its focus on human costs and externalities and not constraints posed by the need for profitability. Until relatively recently, there were few accessible alternatives to profit-oriented innovation for societal problem solving. The advent of information technology, however, has enabled probabilistic systems of problem solving, such as crowdsourcing, that have dramatically decreased the costs involved in knowledge search and knowledge management.

Probabilistic systems that use the 'crowd' have enabled radically lower cost models of fundraising (in the form of crowdfunding) and knowledge sourcing (in the form of crowdsourcing). "Simply defined, crowdsourcing represents the act of a company or institution taking a function once performed by employees and outsourcing it to an undefined (and generally large) network of people in the form of an open call", which can take the form of "peerproduction (when the job is performed collaboratively), but is also often undertaken by sole individuals" (Howe, 2006, p. 5).

Another challenge faced by profit-seeking firms in dealing with large-scale social problems is the scale of investments in innovation and R\&D that are required to sufficiently address these; market-generated innovation and $\mathrm{R} \& \mathrm{D}$ is sensitive to scale due to the risks involved under profit constraints. It is therefore argued that 'first generation' innovation and R\&D cannot sustain the global innovation pipeline that is needed in order to address the challenges discussed above, notwithstanding that these health challenges are but one dimension of the challenges faced by humanity at this point in time.

Another challenge faced by first generation finance, or finance that is tethered to the need to generate profitable returns, is that it also does not sufficiently utilise probabilistic mechanisms to generate funds under conditions that are unprofitable. The new 'second generation' paradigm of crowd-enabled fundraising, in the form of crowdfunding, has potentially heralded in an age of probabilistically enabled fundraising, enabled by the 'crowd'. These developments have heightened what appears to be an increasing tension between the emergence of probabilistically-based second generation (SG) systems and the failure of 'linear' first generation (FG) systems to deliver social innovations, or innovations with large-scale positive externalities that do not necessarily provide opportunities for profit.

\section{RESEARCH OBJECTIVE}

A fundamental and unresolved tension therefore seems to run through the literatures that relate to academic work in general. On the one hand, over the past decades an explosion in the form of exponential growth in information and knowledge has occurred that has been unmatched in human history (Adair \& Vohra, 2003). On the other hand, many problems facing humankind in the form of disease and catastrophic events remain in a state similar to that faced decades ago.

In the face of $R \& D$ failure associated with first generation $R \& D$ (FGR)(Callaghan, 2014a), an alternative is offered in this paper, in the form of second generation innovation (SGI), that is primarily underpinned by second generation R\&D (SGR) and second generation fundraising (SGF). The objective of this article is therefore to present what is potentially an alternative paradigm of societal problem solving based entirely on second generation (SG) processes. A theoretical model of multidimensional problem solving, termed Multidirectional, or 'three dimensional', knowledge creation in the form of Non-Proprietary Crowdsourced R\&D is contrasted with the 
Dyadic, or 'two dimensional', knowledge creation process of Proprietary Crowdsourced R\&D. The argument is made that the proprietary requirements of knowledge in crowdsourced R\&D exist as a boundary condition to theory relating to crowsourcing as a form of innovation. The concept of a 'multiplier effect' is also introduced; that relates to exponential increases in knowledge creation that may result from a relaxation of the proprietary requirements of knowledge generation. It is argued that the exponentially increasing global body of information and knowledge requires a transmission mechanism to translate this increase into an equivalent exponential increase in the outputs of social problem solving. An exponentially increasing body of information, it is argued, therefore requires a 'mechanism' of information processing for this transmission to social problem solving to fully occur; and that such mechanisms already exist, in the form of probabilistic systems of knowledge management such an crowdsourcing.

The paper is structured as follows. First, the alternative paradigm associated with SGI and SGR is outlined and explained in relation to the challenges faced by FGI and FGR. Next, SGI fundraising in relation to its potential to contribute to social innovation is discussed, in the form of crowdfunding. After this, crowdsourcing as a form of SGI and SGR is considered in terms of its potential contribution to social innovation. At this point, a synthesis of these two literatures (crowdsourcing and crowdfunding) is provided, and a model that incorporates both of these is presented; a model of social problem solving that offers a radically reduced cost structure and that is financially sustainable while possibly being able to solve large-scale societal problems. The paper concludes with recommendations for theory and practice, and with the argument that many serious social problems faced by people around the world presently can be solved at this time using this model. The proposed alternative paradigm associated with SGI and SGR is now introduced and discussed.

\section{RESEARCH METHODOLOGY}

This article follows a conceptual methodology, based on a process of theory development. The article is therefore a conceptual work, the outcomes of which are three models that represent different relationships around crowdsourced R\&D. These models suggest certain theoretical predictions about these relationships and how to increase innovative output under certain conditions; and especially conditions where it is not profitable for private, or proprietary, R\&D to be used. The rigour of this method is based on the extent to which the theoretical propositions developed are found to be supported in subsequent research. This is therefore a theory paper, and conforms to the precedent in the literature of what is typically included in such a paper in terms of structure and layout.

\section{THE ALTERNATIVE PARADIGM}

Whereas FGI is fundamentally non-probabilistic in nature, SGI is related to probabilistic mechanisms of innovation, which enable exponential learning (Callaghan, 2014a). Innovation, or the development of new processes and new ways of doing things, can be increased exponentially by using the 'crowd', or by obtaining input from large numbers of people (Howe, 2006). A key problem with this process is that the profitability captured by closed models of innovation is 'traded away' when knowledge is shared (Xia, 2013).

This problem presents as the profitability paradox; using the crowd to generate profitable knowledge has its limits. However, it is argued here that when social innovation, or innovation aimed at solving social problems that is independent of profitability concerns, is the objective, then another set of potentialities seem to arise. If FGI is constrained by proprietary mechanisms, then what is not profitable cannot be undertaken. This should therefore exclude all points past a potentialities frontier that is defined at the outer reaches of profitability.

FGI is also fundamentally constrained by the presence of uncertainty, particularly uncertainty relating to financial returns (Callaghan, 2014a). In contrast, SGI utilises probabilistic mechanisms that seem to be, according to the evidence to date, relatively robust to cost pressures; open source contributors have been found to derive intrinsic rewards from contribution (Lakhani, 2008). Similarly, contributors to certain crowdfunding initiatives have been found to have altruistic motivations (Lakhani, 2008). The notion that non-profit driven innovation and R\&D in the form of SGI can provide an alternative paradigm to their first generation counterparts seems counter-intuitive, in that SGI has, seemingly, not yet emerged to solve large-scale social problems. However, it is argued here that SGI theory 
predicts that this alternative paradigm will emerge, sooner or later, because of its inherent advantages over first generation, or proprietary innovation for societal problem solving.

It is argued that when there is no need to keep knowledge secret, or 'proprietary', then the crowd can act in a truly probabilistic way, producing exponentially increasing 'processing power' as it sources problem-solving inputs.

This may be the potential of SGR. However, a further potential may exist, within the broader realm of SGI; the potential of crowdfunding, or the use of the crowd to source resources, which also has the potential to draw funds from very large numbers of individuals. The rise of crowdfunding is expected to contribute significantly to economic growth, innovation and job creation (Thompson, 2014).

The synthesis of both crowdfunding and crowdsourced R\&D can potentially offer a new, or alternative, paradigm of social innovation, where serious and large-scale social problems can be solved relatively cost effectively. Exponential mechanisms of fund raising can in this way be harnessed while, at the same time, exponential mechanisms of knowledge sourcing can also be enabled, through the reward mechanisms offered for the solving of problems or subordinate components of targeted problems (Stieger, Matzler, Chatterjee and LadstaetterFussenegger, 2012).

The use of probabilistic mechanisms is not new to nature; viruses and bacteria use these mechanisms as forms of 'learning', by harnessing the effects of large numbers (Eshel, 2009). In other words, they also rely on mechanisms related to 'the crowd'. The use of these probabilistic mechanisms to raise funds and to source knowledge to solve serious problems may offer new hope for humankinds' quest to solve social problems.

Having introduced the alternative paradigm associated with forms of SGI such as crowdfunding and crowdsourcing, literature relating to each of these dimensions of SGI is now reviewed, in order to provide context for the development of the model that follows. Literature relating to crowdfunding is now considered.

\section{CROWDFUNDING AS A DIMENSION OF SECOND GENERATION INNOVATION}

Crowdfunding, an "Internet-based mechanism through which individuals solicit small amounts from many donors instead of a single large sum from an institution", is increasingly being used to raise funds for research (Averett, 2013, p. 908). The Web site 'Kickstarter' is an example of a site dedicated to crowdfunding (Averett, 2013), which had raised over $\$ 230$ million for 23000 projects by 2012 (Wasik, 2012).

Creative fields, in particular, have used this site to raise funding; donors typically receive a unit of the work once it has been produced (Averett, 2013). In the wake of the success of Kickstarter, scientific crowdfunding sites have emerged, such as Microryza, Petridish.org, \#SciFund Challenge, and FundaGeek, where donors typically share "the thrill of scientific discovery" as their primary payoff (Averett, 2013, p. 908). Interestingly, ecologists and evolutionary biologists have been amongst the first to take advantage of crowdfunding, as these fields are most closely related to crowdsourcing (Averett, 2013). Crowdfunding has also emerged in the publishing industry; an example is 'Unbound', a crowdfunding publisher launched in 2011, which offers authors $50 \%$ of a successfully published book's profits while allowing contributors to subscribe and contribute amounts for which they receive copies of the books (Allen, 2013).

Time periods are typically set, so that project proposers need to achieve their objectives within the timeframes that they propose, or monies need to be returned (Averett, 2013). By 2011, approximately 452 crowdfunding platforms worldwide had raised about $\$ 1.5$ billion. Publicity, however, is important in order to attract attention from the public (Averett, 2013).

The 'Jumptstart Our Business Startups (JOBS)' act in the USA has enabled equity crowdfunding; entrepreneurs can now sell unregistered shares to the public and other investors over the Internet (Wasik, 2012). This enables crowdfunding by removing the need for Securities Exchange Commission registration; up to a million dollars of stock can be sold each year to investors, and there is no limit as to the numbers of investors (Wasik, 2012). 
The implementation of crowdfunding, however, is not without its challenges and pitfalls. Kickstarter has had to deal with fraudulent applicants (Wasik, 2012). Crowdfunding can therefore pose risks to investors (Thompson, 2014; Wasik, 2012); costs can be imposed on investors through lack of knowledge (Krasteva \& Yildirim, 2013). Nevertheless, uninformed donors have been found to be less generous than those that have more knowledge about a project, or that have had their costs of information reduced (Krasteva \& Yildirim, 2013). Crowdfunding websites are increasingly providing transparency and open communication (Thompson, 2014). Two potential bottlenecks in the crowdfunding process may present themselves in the form of delays associated with payout models and the potential role of varied legal issues (Tomczak \& Brem, 2013).

Notwithstanding these challenges, crowdfunding offers certain advantages. It extends the portfolio of typical sources of investment, building on options such as venture capitalists and business angels (Osnabrugge, 2000). Business angels have been found to typically focus on the reduction of agency risks using an incomplete contracts approach, whereas venture capitalists typically focus on the principle-agent approach (Osnabrugge, 2000). Crowdsourcing might also lessen the risks of investments by investors through its sourcing of smaller amounts, spread over large numbers of people. The 'spread' of crowdfunding might still be in its infancy; growth at this stage might still be led by angel investors and hedge funds (Thompson, 2014). However, angel investment declined following the financial crisis of 2008 (Tomczak \& Brem, 2013).

In less-developed countries, however, the use of crowdfunding is growing quickly (Thompson, 2014). Crowdfunding might offer new opportunities in the developing world; $85 \%$ of these people have mobile phones, with a growing share of 'smart phones' that can enable crowdfunding in its different forms (Thompson, 2014).

There seem to be five distinct crowdsourcing models: (i) the donation model which provides contributors with no stipulated reward and are typically more likely to be associated with non-profit or charitable sectors, (ii) reward models which offer a nominal token in return for contributions, but do not offer a share of earnings or of the project or business, (iii) the pre-purchase model, where the contributor receives the product that an entrepreneur is developing or producing, (iv) the lending or peer-to-peer (P-2-P) model which is typically used when moving a project to the business development stage, and (v) the equity model, where investors receive a stake in the business or profit stream from a project, which usually involves stipulations relating to regulatory regimes (Harrison, 2013). The emergence of crowdfunding, however, might herald a fundamental change in the way financing can enable economic and social activity.

The crowdsourcing model "represents the disintermediation of the finance market as funders and promoters are brought together directly" (Harrison, 2013, p. 286). This radical change has also seen the rise of "new institutional forms, as the crowdfunding platforms themselves play an increased role as actors in the market, notably in the equity model" (Harrison, 2013, p. 286). For Harrison (2013, p. 286), the:

[C]rowdfunding space is still evolving, institutional forms are developing and changing as models are refined, new institutional collaborations (e.g. between equity platforms and business angel networks) are emerging and new challenges, particularly regulatory challenges, are being encountered.

Under these conditions of change, new patterns in the emergence of different institutional forms of finance are therefore expected to also emerge (Harrison, 2013); what this has in common with the use of crowdsourcing is perhaps the rise of 'the crowd'. With the new potentialities that arise at the nexus of crowdfunding and crowdsourcing it might be possible to leverage these to more effectively solve social problems. A synthesis of crowdfunding and crowdsourcing developed into a platform or a model of societal problem solving might offer new potentialities because the probabilistic mechanisms of the crowd are harnessed.

In this paper, it is argued that the tension between the rapid and exponential increases in information and knowledge available to stakeholders on the one hand, and the slow pace of progress in the achievement of social goals that are not aligned with profit-seeking research, on the other hand, is fundamentally untenable. It is possible that this situation has persisted due to a reliance on first generation innovation (FGI) systems, and first generation research and development (FGR), which are uniquely suited to the market system and the constraints to innovation associated with the need for commercialised solutions in resource scarce environments. In short, FGR might be 
unsuited to social innovation that is on a scale unsuited to solutions requiring business model innovation, or to social innovation in general that is not profitable for private firms to undertake.

It is therefore argued that the use of SGI and SGR together, in a 'synthesis' model of sorts, may potentially offer a new paradigm in problem solving that might be able to transcend the limitations of FGI and FGR. SGI and SGR both make use of probabilistic mechanisms associated with economies of scale, which exponentially increase their problem solving potential. Similarly, the use of SGI and SGR are based on 'open innovation' models, which can make them less dependent on the use of closed business models (Chesbrough, 2007) and possibly also profitability requirements if used for social innnovation.

The implications of this argument are multiple. First, in the face of urgent threats to human life that can be neutralised through the application of knowledge, SGI systems could be implemented immediately; a time advantage may exist if social problems can be solved with resources that already exist. Second, such threats can be neutralised at a significantly lower cost; a cost advantage. Third, while private commercial research and development $(R \& D)$ can continue in most areas, social innovation and R\&D may be pursued on almost any scale; a scale advantage. It is, however, acknowledged that these implications are based on an argument, and are, as yet, untested. Nevertheless, it is the role of conceptual papers such as this one to suggest areas for theorising and theory testing in management research.

The primary argument made in this paper, therefore, is that timeous adoption of SGI is necessary, and that the use of both crowdfunding and crowdsourcing in the form of a model to address social problem solving might yield new possibilities to address problems that are not profitable for firms to address. In order to make this argument, certain literature was reviewed in the above sections that relates to crowdfunding. At this juncture, literature that relates to crowdsourcing is now reviewed in order to provide a basis for the model that is presented thereafter; a model that provides a system of crowdfunding coupled with crowdsoured R\&D that offers a social problem solving approach almost entirely based on SGI.

\section{CROWDSOURCING AS A DIMENSION OF SECOND GENERATION INNOVATION}

Different categorisations of crowdsourcing have been offered. Crowdsourcing has been classified as (i) internal crowdsourcing, (ii) community crowdsourcing, (iii) open crowdsourcing, (iv) and broker-enabled crowdsourcing, according to dimensions such as structural properties, the nature of collaboration and the governance of crowdsouring networks (Simula \& Ahola, 2013). What seems atypical of other forms of work are the motivations of those that typically contribute to crowdsourcing projects. Many open source contributors have been found to be motivated intrinsically more than extrinsically; reportedly contributing on account of enjoyment, creativity, intellectual stimulation and learning (Lakhani \& Wolf, 2003).

One experiment highlights the importance of meaningfulness for crowdsourcing effectiveness. An experiment was run, using 2500 workers from Amazon's Mechanical Turk, which formed a crowsourced labour market (Chandler \& Kapelner, 2013). These workers labelled medical images, and were divided into three groups; (i) Group 1, who were not provided with information about the context of their work and were also told that their work would be discarded; (ii) Group 2, who were not told anything about the purpose of the task (the control group); and (iii) Group 3, who were told that they were labelling tumour cells to help medical research (Chandler \& Kapelner, 2013). Group 3 were found to have higher levels of output with no significant difference in quality from the control group and Group 1 were found to have lower levels of quality with no significant difference in quantity than the control group (Chandler \& Kapelner, 2013).

Other research suggests that scientists may 'pay' to work as scientists, preferring lower wage work if it is scientific in nature (Stern, 2004). It is this 'meaningfulness' that seems to underlie certain dimensions of the motivational, or intrinsic, profile of incentives that have been found to be associated with crowdsouring inputs. Putting problem solving to the crowd might be more likely to include those with different motivations; the motivational diversity that has contributed to the success of open source software development (Lakhani \& Wolf, 2003), a form of crowdsourcing. 
Crowdsourcing, therefore, has the potential to solve problems that were until now considered to be unsolvable (Brabham, 2008), and is particularly well suited to social innovation (Fuller, Hutter and Fries, 2012). A new paradigm of knowledge management has been enabled through crowdsourcing. The applications of crowdsourcing to solve problems taken root in diverse contexts. For example, crowdsourcing has been used to develop virtual conversational agents (Rossen \& Lok, 2012), to develop heuristic algorithms for software testing (Tung \& Tseng, 2013), for product development (Djelassi \& Decoopman, 2013), for academic student research (Bates \& Lanza, 2013), and for gaining external input into organisational improvement (Simula \& Vuori, 2012). A particularly important benefit of crowdsourcing is that it can 'collapse' geographic distances between people engaged in problem solving (Schall, 2013).

In an era where private $R \& D$ is limited in its contribution of positive externalities due to the constraints associated with the need to generate a financial return, the innovation 'pipeline' for solving social health problems seems to have taken a certain shape: the 'chronification' of health solutions. This refers to a tendency to produce effective treatments that need to be taken over periods of time, instead of cures. This is the 'Golden Goose' model of pharmaceutical medicine; producing cures (killing the Golden Geese) will be less profitable than producing chronic solutions that need to be taken continuously. This is not to suggest there is malevolence on the part of private providers, but rather that the profit constraints faced by these organisations might tend to 'shape' industry provisions. This 'chronification model' seems simply to be a more profitable model, given the constraints faced by profit-seeking R\&D (FGR). However, given the potentialities offered by SGI, it may be possible to transcend these profitability constraints and move to a curative paradigm in health-related social innovation, because of the different economic structure that underlies SGI.

\section{THE FAILURE OF FIRST GENERATION INNNOVATION}

Rooted in the process perspective of management (Langley, Smallman, Tsoukas \& Van de Ven, 2013), the failure of FGI is taken to be a failure of its systems of finance (first generation finance) that are shaped and dictated by the profit mechanism. Profit-seeking R\&D investments are typically sub-optimal; private investments cannot be reliably relied on to solve social problems, no matter the market structure. The "level of investment in research and development is likely to be too low, from a social point of view, whether market structure is nearly atomistic, a highly concentrated oligopoly, or something in between" (Martin \& Scott, 2000, p. 438). Further, limited "appropriability, financial market failure, external benefits to the production of knowledge, and other factors suggest that strict reliance on a market system will result in underinvestment in innovation, relative to the social desirable level" (Martin \& Scott, 2000, p. 438).

FGR might be taken to operate according to 'archipelago', or in the form of islands, as an iterative process where duplication and knowledge silos predominate (Callaghan, 2014a). Arguably, this is a form that arises because of the need to keep knowledge and R\&D advances 'proprietary', or secret, until they can be protected using intellectual property provisions and brought to market. This form of research, however, is perhaps not problematic for most research fields where investments in R\&D are profitable, notwithstanding the uncertainty that surrounds such investments (Martin \& Scott, 2000).

The argument made here is that this profit-oriented structure of R\&D needs to be supplemented, not replaced, by SG research processes, particularly when it comes to needed social innovations that are inherently not profitable, or where uncertainty mitigates against clear knowledge of potential profitability in the form of net present value.

It is argued that SGI is therefore not taken to be appropriate in all contexts. It is perhaps best suited to instances where market failure is present, but not to where the market can be more effective and efficient (Callaghan, 2014a). Market applications of SGI are also not expected to necessarily challenge FGI, but be complementary (Callaghan, 2014a). SGI will perhaps offer a more modest contribution as a complement to FGI in pursuit of profit-seeking financing and R\&D opportunities. However, when it comes to large-scale social problems, which typically require financial investments yet have little chance of profitable outcomes, it is argued that SGI is the appropriate methodology because it is better suited to solving these types of problems. Another dimension of 
difference between academic fields that may indicate a need for SGI is the inherent complexity of a particular field (Callaghan, 2014a).

An example of a field that seems to be uniquely resistant to FGI (and inherently more suited to SGI) is proteomics. Proteomics is the study of the protein structures that underlie genomics (Blackstock \& Weir, 1999). The "goal of proteomics is a comprehensive, quantitative description of protein expression and its changes under the influence of biological pertubations such as disease or drug treatment...Mechanism databases [provided by proteomics] provide a roadmap toward effective therapeutic intervention that is more direct than that offered by conventional genomics approaches" (Anderson \& Anderson, 1998, p. 1853). This field can hold significant potential for the development of cures for diseases because its findings underlie gene therapy and discoveries relating to the human genome. It is a 'source' field because it underlies what is done in other health fields.

However, there is a fundamental problem that has constrained progress in this field. It is extremely complex (Anderson \& Anderson, 1998; Blackstock \& Weir, 1999). It exists at the nexus of a wide variety of different scientific fields, including computer science, biology, chemistry, imaging, and others. The primary problem faced by the field is the need for information and knowledge, and the bioinformatics required to manage this data. It is because of this constraint that SGI can perhaps offer the greatest chance of delivering breakthroughs in this field. Breakthroughs in this field might, in turn, offer a better chance at the emergence of a new paradigm in social problem solving that relates to healthcare.

With the advent of internet technology, SGI has been enabled. The emergence of these enabling conditions might have provided a rich context for new paradigms to interact, and to spur progress in social innovation. Proteomics, as field, is also newly emerged; the term 'proteome' emerged in 1995; to name the protein complement of a genome, and this new discipline emerged (Blackstock \& Weir, 1999). The costs of analysis and progress in the field, however, are reducing rapidly, and health-related advances are looming larger as time progresses (Blackstock \& Weir, 1999).

Crowdsourcing is increasingly being used in proteomics research (Barsnes \& Martens, 2013). It is possible that the probability of 'breakthroughs' in science can be increased through the emergence of SGI, particularly if stakeholders support the development of SGI. The arguments made in this paper, however, are dependent upon the assumption that SGI is effective, and can deliver against these promises. The successes of SGF, in the form of crowdfunding, have been considered above. Certain successes of SGR are now considered, in order to support these arguments.

There is general consensus across the literature that the efficiency and effectiveness of problem solving can be dramatically improved through the application of crowdsourcing to generate ideas (Afuah \& Tucci, 2012). However, the specific extent to which crowdsourcing can have an impact is contingent upon the unique characteristics of the problem, the specific knowledge required, the characteristics of the crowd and the solutions themselves (Afuah \& Tucci, 2012).

In contrast to Howe's (2006) definition, however, crowdsourcing is not taken here to exist only when a company commercialises crowdsourced knowledge, but instead refers to any part of the innovation process that involves the use of the crowd to source knowledge and information. Following Callaghan (2014a, p. 18), crowdsourcing is therefore taken to represent "the use of distributed systems of communication that are targeted at the 'crowd', whether for information gathering or for any other part of the innovation process". According to this definition, there have been many successful historical applications of crowdsourcing; and example of this is idea competitions (Stieger et al., 2012), some examples of which include the Longitude Prize in 1714 and the Alkali Prize in 1783 (Brown, 2012). More recent successes have been enabled by the technological changes associated with today's postmodern society (Goneos-Malka, Grobler \& Strasheim, 2013) such as Web 2.0 technologies and their social network capabilities (Stieger et al., 2012).

InnoCentive, launched by the pharmaceutical firm Eli Lilly (Stieger et al., 2012), self-described as the eBay of innovation (Lakhani, 2008), was one of the first contemporary crowdsourcing platforms to demonstrate 'proof of concept', or the potential of crowdsourcing to successfully solve challenging scientific problems using the crowd 
(Allio, 2004; Breen, 2002; Brown, 2012; Boswell, 2003; Lonstein \& Lakhani, 2011), particularly problems that could not efficiently be solved in-house (Stieger et al., 2012); examples of these include attempts to address social problems such as the development of tuberculosis drugs (A.M.T., 2008), the management of environmental problems (Lakhani, 2008) and the management of worldwide water issues (ITT, 2011).

The rise of crowdsourcing in social problem solving seems also to be related to the slow progress of medical research. Dissatisfaction with the slow pace of problem solving in medical research has led to citizen activism (Saparito, 2013) and crowdsourcing has shown its effectiveness in sourcing R\&D input in areas such as protein folding, genomics data collection, disease research and other forms of drug R\&D (Torr-Brown, 2013).

Implicit in the discussion of the potential of crowdsourcing to solve social problems are the shortcomings of FGI (Callaghan, 2014a). The above sections provided an overview of the literature in support of the argument that a synthesis of SGF and SGR, or of crowdfunding and crowdsourced R\&D, might offer a model of societal problem solving that is primarily probabilistic in nature and based on the principles of SGI. It was argued that this synthesis could both generate the resources necessary to complement the SGR process as well as generate the informational and knowledge inputs necessary to be effective. At this juncture, the Global Model is briefly introduced, prior to the discussion of the Synthesis Model.

This Global Model is an application of SGR to societal problem solving, which takes the form of a crowdsourcing platform that directs information and knowledge inputs toward the solving of one particular globalscale problem at a time (Callaghan, 2014a). For example, if every country in the world were to pledge their health budgets that relate to one particular problem, then a significantly large incentive for crowdsourced R\&D could be enabled. The idea behind the Global Model is that if all 170 or so countries in the world (those that are able to) could pledge their yearly budgets for this problem for one year, five years in advance, then the reward would exist for a crowdfunded solution to the problem. The money would only need to be paid by countries if a solution was found; countries cannot lose because if no complete solution is found then nothing needs to be paid (Callaghan, 2014a). If the solution is found, then countries gain the equivalent of the net present value of all spending that would have continued into the future until a cure or solution was found in another way.

The idea behind the Global Model is simple, but can be extended to different problems. What is different, however, about the Synthesis Model is that it can account for its own genesis; a SGI project of this nature can use SGF to 'seed' itself using the crowd, and SGR to capture information and knowledge value from the crowd. As argued by Callaghan (2014a), these SG processes can tap into, and make use of, processes used in nature that have been extraordinarily successful for biological organisms and other forms of life, that also use these processes for 'learning'.

\section{THE SYNTHESIS MODEL}

The Synthesis Model is premised on the notion that the entire innovation process can be 'unhinged', or 'decoupled' from FGI processes; so that the process is primarily based on the probabilistic paradigm offered by SGI, using both crowdfunding and crowdsourcing. This model is therefore based on the notion that learning and problem solving using the crowd can increase its chances of success, or the probability of finding solutions, if the problem solving is spread across an extremely large number of potential solvers. If economies of scale are enabled, on a sufficiently large scale, and if the 'learning' in the form of knowledge and information is 'fed back' into the crowd for further feedback, it might be possible to exponentially increase the rate of learning and problem solving. This is illustrated in Figure 1. 
Contributor

(Provider)

from the Crowd

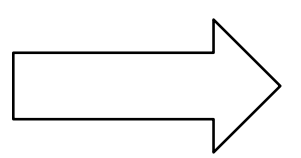

Seeker

(Receiver)

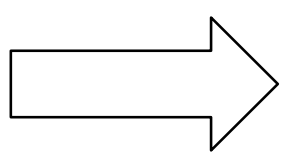

A. Dyadic or Two Dimensional Model of Proprietary Crowdsourced R\&D

Contributors

(Providers) from

the Crowd
Seeker

(Receiver)
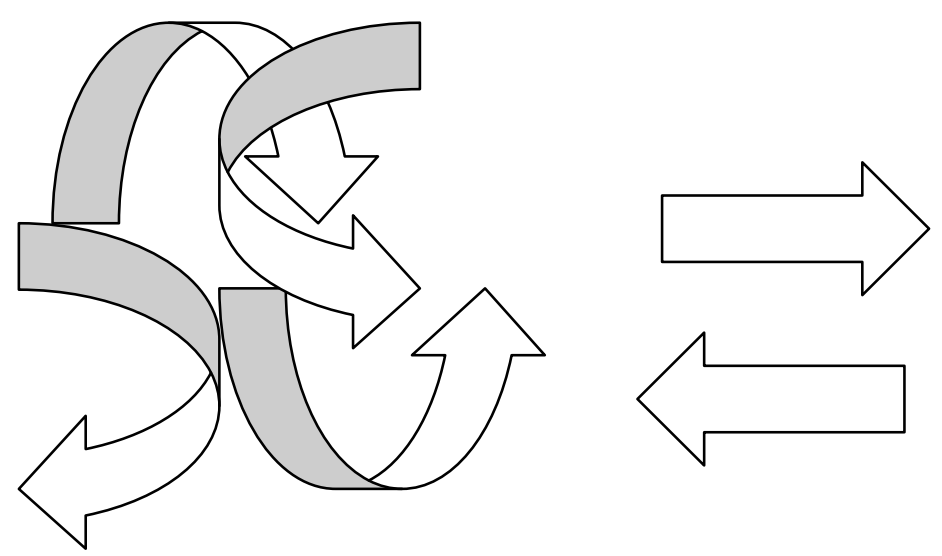

B. Multidirectional or Three Dimensional Model of Non-Proprietary Crowdsourced R\&D

Figure 1: The Dyadic Model of Proprietary and Multidirectional Model of Non-Proprietary R\&D

This 'multiplier effect' can also transcend the 'linear' crowdsourcing model, which uses a dyadic process between contributor (provider) and knowledge seeker (receiver) that needs to keep crowdsourced information 'proprietary' or to some extent 'secret' (so that its commercialised applications offer a knowledge advantage over competitors which in turn can translate into competitive advantage). This (that knowledge needs to be kept secret in order to provide competitive advantage) is a problem posed by profit-seeking R\&D that is less of a problem for the Synthesis Model, which exists as a social innovation platform because knowledge created by this model is shared, processed and made available to all problem solvers on a continuous basis. In this way, the crowd is able to accelerate its learning because knowledge and learning is fed back into it. This feedback can be instantaneous.

In this way, the dyadic, or two dimensional, form of contribution necessitated by private (proprietary) crowdsourced R\&D is replaced by multidirectional, or three dimensional, flows of shared information (which are non-proprietary because they are not kept secret from the crowd but are instead fed back into the crowd). In other words, proprietary crowdsourced $\mathrm{R} \& \mathrm{D}$ undertaken for commercial benefit needs to protect the information provided by the 'provider', or contributor, to the commercial 'receiver', or seeker (Howe, 2006). This knowledge needs to remain secret, or proprietary, in order for it to be protected from falling into the hands of competitors, which is why patents and other forms of intellectual property protection are so important (Caviggioli \& Ughetto, 2013). This knowledge relationship between the provider and the receiver is termed a dyadic relationship for the purposes of this model, because it reflects an interaction between two 'parties' which deliberately excludes third parties (to exclude potential competitors). Knowledge gained is lost to the crowd, or is not immediately fed back into it. When multiple 
sources of knowledge can provide inputs while at the same time this knowledge is fed back into the crowd (because there is no need to keep this knowledge secret) then according to this model the knowledge creation process can be accelerated. This acceleration, based on the increased, and multiple directions of these flows (shown in Figure 1), might be able to provide exponential learning improvements. This process is perhaps better suited for solving social problems that private dyadic crowdsourced R\&D cannot solve because incentives (Caviggioli \& Ughetto, 2013) are absent. The proprietary nature of crowdsourced R\&D is therefore considered an important boundary condition to theory around the acceleration of knowledge creation through crowdsourced R\&D.

SGI is not independent of resource constraints, however, and still requires funding. Crowdsourced contributions still need to be incentivised (Lakhani, 2008). Crowdfunding might enable more efficient financing of crowdsourced knowledge inputs (Harrison, 2013), but fundraising is still the dominant constraint to SGI driven social problem solving.

The Synthesis model essentially entails the use of crowdfunding to generate resources (Harrison, 2013) followed by the use of crowdsourcing to generate knowledge and information inputs in support of problem solving (Howe, 2006). If the Synthesis model is applied to private problem solving, it might still be effective, but its dyadic form is expected to not be able to offer the same potential as in its social problem solving form which is not constrained by the need to keep information secret. The Synthesis Model is illustrated in Figure 2.

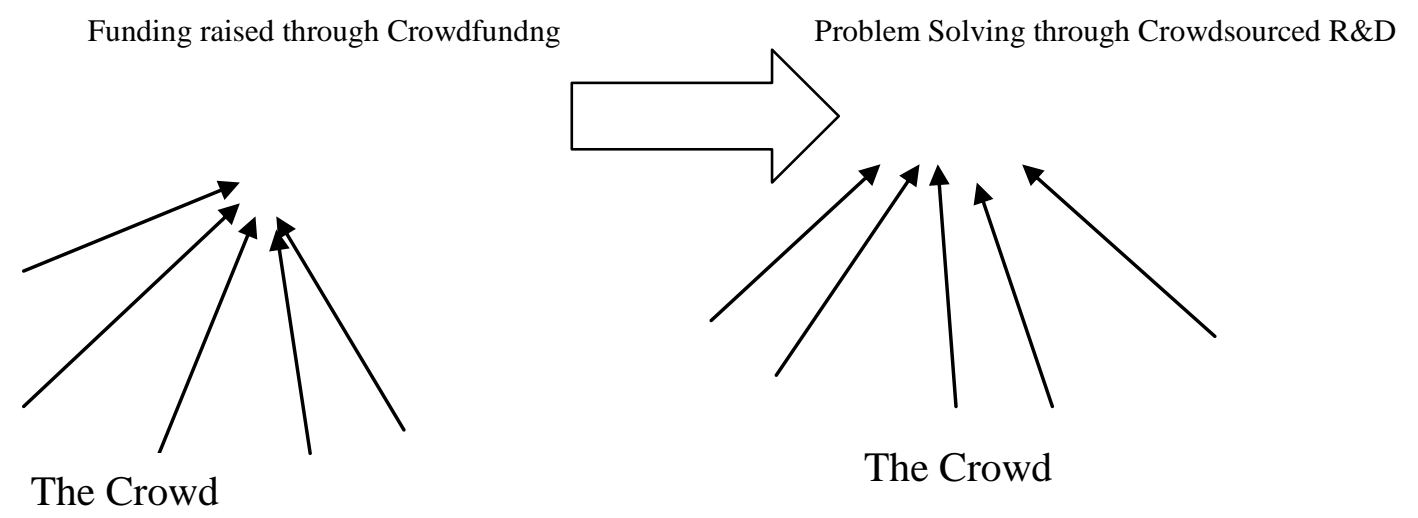

Figure 2: The Synthesis Model Based On Harnessing Synergies Between Crowdfunding And Crowdsourced R\&D For Societal Problem Solving

The Synthesis Model builds on the advantages of both crowdfunding (Harrison, 2013) and crowdsourced problem solving (Howe, 2006), in the form of crowdsourced R\&D (Callaghan, 2014a). By building sustainability into the model through a funding source, and by using the crowd to provide for both processes, certain advantages of the SGI-based Synthesis Model are expected over FGI alternatives. The Synthesis Model might be appropriate for a wider and more diverse range of interest groups to use because of these advantages. First, the model may offer problem-solving benefits in terms of cost and time. Smaller groups of interested stakeholders with an interest in solving a particular problem may therefore find this model useful. It may, to some extent, be relatively selfsustaining, which puts the probabilistic mechanisms of SGI into the hands of 'grassroots' stakeholders.

Second, the model might be relatively scale independent; it can potentially be applied on a large scale to solve serious global problems with a world-wide impact as well as to smaller projects. Curing cancer or solving problems associated with research on ageing, for example, may be ideal candidates for a powerful and focused application of the Synthesis model, because these are problems that millions of people (more of the crowd) are especially interested in (Callaghan, 2014a).

Third, the model may offer the potential to transcend many of the constraints to innovation (Callaghan, 2014a) experienced by profit-seeking firms. Using SGF and SGR to transcend the limitations posed by the need to ensure profitability can perhaps set into motion an entirely new 'economics' of social problem solving. 
As the structures of incentives related to societal problem-solving (Martin \& Scott, 2000) are re-aligned, and capital structures transmit resources to problem solving productivity in a different way (Harrison, 2013), the shift from a reliance on the profit-oriented systems of FGI toward SGI systems (that free up processes to only focus on outputs) may offer entirely new ways to conceptualise problem-solving. The Synthesis Model might be uniquely suited to solving societal problems through its use of crowdsourced $R \& D$ in instances where it is not profitable for private or proprietary $\mathrm{R} \& \mathrm{D}$ to do so.

This is not to say that profit-seeking innovation is ineffective where returns do exist. SGI is a complementary system of innovation that might be best suited to social innovation that is inherently not profitable for firms (Callaghan, 2014a).

SGI might also not be optimally suited to profit-seeking innovation because the 'proprietary' or FGI models of innovation require information and knowledge to be kept 'secret' from competitors, or require protections in terms of intellectual property stipulations (Caviggioli \& Ughetto, 2013). SGI therefore offers systems that are robust to these constraints (the need for profitability), but might not be ideally suited to profit-oriented R\&D. FGI might be more appropriate for profit-seeking innovation, and SGI should be seen as complementary to, and not a replacement of, FGI. The paradigm of FGI seems to primarily be deficient in its ability to deal with social problems that are not typically within ambit of market problem solving.

Scientific advances are to some extent a function of the values and subjective perceptions and norms which are shared by groups of academics, which create 'paradigms' (Kuhn, 1970). Certain other research has demonstrated the salience of values and the potential lack of innovativeness in academic contexts (Callaghan, 2014b). It is possible that successes in problem solving based on SGI might spearhead more academic interest and theorising related to what might possibly be a new paradigm in social innovation. Time will undoubtedly tell whether this potential will manifest in a new paradigm of social problem solving or not. However, even if the contribution of SGI is modest, it is hoped that it will make a contribution to problem solving in some way. Further research should continue to grapple with the challenges faced by innovation management in the face of social problems that cannot appropriately be solved by firms.

In the above sections, what was described as an alternative paradigm in social innovation was introduced in relation to two forms of SGI, notably crowdfunding, conceptualised as a form of second generation fundraising, or SGF, and crowdsourcing, as a form of second generation R\&D, or SGR, and a model was suggested for how both could be used together for social problem solving.

\section{CONCLUSION}

This paper set out to make the argument that the global innovation pipleline that needs to provide social innovations is constrained by the structures of markets, and by the need to meet profitability criteria. This type of structure of innovation was broadly classified as first generation innovation, or FGI. An alternative paradigm in social innovation was offered, one almost entirely based on second generation innovation (SGI), which used crowdfunding, a type of second generation fundraising (SGF), together with crowdsourcing, a type of second generation research and development (SGR), as components of a relatively self-sustaining model of social innovation, termed the Synthesis Model. Prior to the discussion of the Synthesis Model, The Dyadic Model of Proprietary Crowdsourced R\&D was contrasted with the Multidirectional Model of Non-Proprietary Crowdsourced R\&D. It was argued that the proprietary requirements of knowledge can act as a primary constraint to the acceleration of knowledge creation in the context of crowdsourced R\&D. The Synthesis Model was then presented. This was a model of crowdsourced R\&D that was based entirely on SGI principles, with some dimension of financial sustainability built into the model- in the form of a crowdfunding component, which was also based on SGI principles. It was argued that this model of social innovation may have certain advantages over FGI models of innovation. For example, the Synthesis Model may be relatively scale independent in its generation of knowledge outputs- it might be used by small- or large-scale projects to generate its own funding and to generate its own information and knowledge inputs to solve knowledge problems, and specifically social innovation problems. It was stressed, however, that SGI is not a substitute or a replacement for FGI, or profit-seeking innovation, but a complementary form of innovation that is best applied in cases of social problem solving that are associated with 
significant positive externalities but which are not inherently profitable. It was argued that this article makes a contribution to the literature in that it offers a model of how social innovation can potentially be undertaken in contexts where it is not profitable for private, or proprietary, R\&D to do so. It is hoped that further research might build on these models because the positive externalities created by successful societal problem solving may benefit a wide range of societal stakeholders; whereas this benefit cannot be taken into account in private R\&D because these positive externalities do not accrue directly to a firm.

\section{AUTHOR INFORMATION}

Chris William Callaghan is an Associate Professor in the School of Economic and Business Sciences of the University of the Witwatersrand. He manages the Knowledge and Information Economics/Human Resources Research Agency (KIEHRA) within the School. His research explores individual and organisational performance across different contexts, with a particular focus on how research can make a contribution to improving the lives of people through problem solving. E-mail: chris.callaghan@wits.ac.za

\section{REFERENCES}

1. Adair, J.G., \& Vohra, N. (2003). The Explosion of Knowledge, References, and Citations. American Psychologist, 58(1), 15-23.

2. Afuah, A., \& Tucci, C. L. (2013). Dialogue. Academy of Management Review, 38(3), 457-460.

3. Ajumobi, K. 2014. War against polio: Nigeria reports single case in 2014. Available at: http://businessdayonline.com/2014/04/war-against-polio-nigeria-reports-single-case-in-2014/ (Accessed 6 April 2014)

4. $\quad$ Allen, K. 2013. Unearthing Crowd-Funded Publishing. EContent, November, 15.

5. Allio, R. (2004). CEO interview: the InnoCentive model of open innovation. Strategy \& Leadership, 32(4), 4-9.

6. A.M.T. (2008). TB Alliance picks InnoCentive solvers. Chemical \& Engineering News, 86(50), 17-17.

7. Anderson, N.L., \& Anderson, N.G. (1998). Proteome and proteomics: New technologies, new concepts, and new words. Electrophoresis, 19(11), 1853-1861.

8. Averett, N. (2013). With Funding Tight, Researchers Tap the Public. BioScience, 63(11), 908.

9. Barsnes, H., \& Martens, L. 2013. Crowdsourcing in proteomics: public resources lead to better experiments. Amino Acids, 44(4), 1129-1137.

10. Bates, J. A., \& Lanza, B. A. (2013). Conducting Psychology Student Research via the Mechanical Turk Crowdsourcing Service. North American Journal of Psychology, 15(2), 385-394.

11. BBC. (2013) WHO urges information sharing over novel coronavirus. Available at:

12. http://www.bbc.co.uk/news/health-22649922 (Accessed 30 May 2013)

13. Blackstock, W.P., \& Weir, M.P. (1999). Proteomics: quantitative and physical mapping of cellular proteins. Trends in Biotechnology, 17(3), 115-121.

14. Boswell, C. (2003). CMR Technology Watch: InnoCentive and Web-Based Collaborative Innovation. Chemical Market Reporter, 263(154), 5.

15. Brabham, D. C. (2008). Crowdsourcing as a Model for Problem Solving: An Introduction and Cases. Convergence: The International Journal of Research into New Media Technologies, 14(1), 75-90.

16. Breen, B. (2002). Lilly's R\&D Prescription. Fast Company, 57, 44-46.

17. Brown, J. (2012). Harnessing the Power of the Crowd. Public CIO, 10(2), 16-21.

18. Callaghan, C.W. (2014a). R\&D Failure and Second Generation R\&D: New Potentialities. Mediterranean Journal of Social Sciences, 5(3), 11-24.

19. Callaghan, C.W. (2014b). Research Productivity and Values. Mediterranean Journal of Social Sciences, 5(1), 453-465.

20. Caviggioli, F., \& Ughetto, E. (2013). The drivers of patent transactions: corporate views on the market for patents. $R \& D$ Management, 43(4), 318-332.

21. Chandler, D., \& Kapelner, A. (2013). Breaking monotony with meaning: Motivation in crowdsourcing markets. Journal of Economic Behavior \& Organization, 90, 123-133.

22. Chesbrough, H. (2007). Why companies should have Open Business Models. MIT Sloan Management Review, 48(2), 1-22. 
23. Djelassi, S., \& Decoopman, I. (2013). Customers' participation in product development through crowdsourcing: issues and implications. Industrial Marketing Management, 42(5), 683-692.

24. Fuller, J., Hutter, K., \& Fries, M. (2012). Crowdsourcing for Goodness Sake: Impact of Incentive Preference on Contribution Behavior for Social Innovation. Advances in International Marketing, 11(23), 137-159.

25. Goneos-Malka, A., Grobler, A., \& Strasheim, A. (2013). Suggesting new communication tactics using digital media to optimise postmodern traits in marketing. Communicatio: South African Journal for Communication Theory and Research, 39(1), 122-143.

26. Halifax, Justine, (2013), Superbugs immune to antibiotics a threat to humans as big as terrorism or climate change. [Online] Available:

27. http://www.birminghammail.co.uk/lifestyle/health/superbugs-immune-antibiotics-bigger-threat-3410907 (May 30 2013)

28. Harrison, R. 2013. Crowdfunding and the revitalisation of the early stage risk capital market: catalyst or chimera? Venture Capital: An International Journal of Entrepreneurial Finance, 15(4), 283-287.

29. Howe, Jeff, (2006). The Rise of Crowdsourcing. Wired Magazine. [Online] Available:

30. http://sistemas-humano-computacionais.wdfiles.com/local--files/capitulo\%3Aredessociais/Howe The Rise of Crowdsourcing.pdf (May 27, 2013).

31. ITT. (2011). ITT launches US\$5000 water challenge on InnoCentive. Filtration Industry Analyst, 4, 5-5.

32. Krasteva, S., \& Yildirim, H. (2013). (Un)Informed charitable giving. Journal of Public Economics, 106, Krishnan, J. 2014. Panic as deadly Ebola virus spreads across West Africa. Available at: http://www.independent.co.uk/news/world/africa/panic-as-deadly-ebola-virus-spreads-across-west-africa9241155.html (Accessed 6 April 2014).

33. Lakhani, Karim, (2008). InnoCentive.com (A). Harvard Business School. [Online] Available: http://www.innocentive.com/files/node/casestudy/case-study-harvard-business-school-studyinnocentive.pdf. (December 28, 2013)

34. Lakhani, K. R., and Wolf, R. G. (2005) Why Hackers Do What They Do: Understanding Motivation and Effort in Free/Open Source Software Projects. In Feller, J., Fitzgerald, B., Hissam, S., and Lakhani, K. R. (Eds). Perspectives on Free and Open Source Software. Available at: http://jpkc.hebtu.edu.cn/NR/rdonlyres/Sloan-School-of-Management/15-352Spring-2005/D2C127A9B712-4ACD-AA82-C57DE2844B8B/0/lakhaniwolf.pdf . (Accessed 9 June 2013).

35. Langley, A., Smallman, C., Tsoukas, H., \& Van de Ven, A. 2013. Process Studies of Change in Organization and Management: Unveiling Temporality, Activity, and Flow. Academcy of Management Journal, 56, 1-13.

36. Lonstein, E., \& Lakhani, K.R. (2010). InnoCentive.com (B). Harvard Business School Cases, 1-3.

37. Maher, K, (2013). The Drugs Don't Work. Time Magazine. Available:

38. http://www.bbc.co.uk/news/health-22649922 (May 30, 2013).

39. Martin, S., \& Scott, J. T. (2000). The nature of innovation market failure and the design of public support for private innovation. Research Policy, 29, 437-447.

40. McKenna, M. (2014). Sneak Peek: What the White House is Thinking About Antibiotic Resistance. Available at: http://www.wired.com/2014/04/pcast-resistance/ (Accessed 6 April 2014).

41. Osnabrugge, M. (2000). A comparison of business angel and venture capitalist investment procedures: and agency theory-based analysis. Venture Capital, 2(2), 91-109.

42. Rossen, B., \& Lok, B. (2012). A crowdsourcing method to develop virtual human conversational agents. International Journal of Human-Computer Studies, 70, 301-319.

43. Saparito, B. (2013). The Conspiracy to End Cancer. Time Magazine, April, 20-27.

44. Schall, D. (2013). Automatic Quality Management in Crowdsourcing. IEEE Technology \& Society Magazine, 32(4), 9-13.

45. Simula, H., \& Ahola, T. (2014). A network perspective on idea and innovation crowdsourcing in industrial firms. Industrial Marketing Management. Available at: http://www.sciencedirect.com/science/article/pii/S0019850113002289 (Accessed 9 April 2014).

46. Simula, H., \& Vuori, M. (2012). Benefits and Barriers of Crowdsourcing in B2B firms: Generating ideas with Internal and External Crowds. International Journal of Innovation Management, 16(6), 1-19. 
47. Siu, Twinnie., \& Pomfret, James. (2013). Hong Kong confirms $1^{\text {st }}$ death from H7N9 bird flu. MSN News. [Online] Available at: http://news.msn.com/world/hong-kong-confirms-1st-death-from-h7n9-bird-flu. (December 27, 2013)

48. Stieger, D., Matzler, K., Chatterjee, S., \& Ladstaetter-Fussenegger, F. (2012). Democratizing Strategy: How Crowdsourcing can be used for Strategy Dialogues. California Management Review, 54 (4), 44-68.

49. Stern, S. (2004). Do scientists pay to be scientists? Management Science, 50(6), 835-853.

50. Thompson, L. (2014). Is Crowdfunding Really a Capital Raising Boon? Boards \& Shareholders www.complianceweek.com, February, 56-57.

51. Tomczak, A., \& Brem, A. 2013. A conceptualized investment model of crowdfunding. Venture Capital, 15(4), 335-359.

52. Torr-Brown, S. (2013). Crowdsourcing for Science and Medicine: Progress and Challenges. The Journal of OncoPathology, 1(2), 75-81.

53. Tung, Y., \& Tseng, S. (2013). A novel approach to collaborative testing in a crowdsourcing environment. Journal of Systems and Software, 86(8), 2143-2153.

54. Wasik, J. (2012). The Brilliance (and Madness) of Crowdfunding. Forbes, 144-146.

55. Xia, T. (2013). Absorptive capacity and openness of small biopharmaceutical firms- a European UnionUnited States comparison. $R \& D$ Management, 43(4), 333-351.

56. Zia, A. (2014). Newly diagnosed child brings polio cases to 40. Available at: http://tribune.com.pk/story/691219/newly-diagnosed-child-brings-polio-cases-to-40/ (Accessed 6 April 2014). 


\section{NOTES}

